\title{
HERPETOFAUNA AND FISH
}

\section{SKIN PIGMENTATION CHANGE IN TIGER SALAMANDERS, Ambystoma tigrinum, FROM ALBERTA}

\author{
DANIEL F. BRUNTON, 216 Lincoln Heights Road, Ottawa, Ontario K2B 8A8
}

An adult male Tiger Salamander (Ambystoma tigrinum) captured in Bow Valley Provincial Park near Canmore, Alberta in August 1977 has been maintained in captivity for 20 years. This apparently represents the oldest known individual of this species $(21.5+$ years). A substantial reduction in the number and extent of irregular black markings on the dorsum and sides of the salamander during its period of captivity is documented. Most pigmentation change occurred within the first three to six years of captivity. Similar changes were also observed on a female Tiger Salamander maintained in captivity for a shorter period. Regardless of the cause(s) for these changes, this confirms. that subspecific identification of individual Tiger Salamander specimens should not be based entirely on pigmentation pattern.

Dunn (1940) describes seven subspecies of the Tiger Salamander, Ambystoma tigrinum (Green), in North America. His diagnoses are heavily dependent on the pattern of light and dark pigmentation on the dorsum and sides of adults. This treatment has been widely accepted and is followed by Stebbins (1966), Gehlback (1967) and others. Dunn (1940) and Gehlback (1967) note, anecdotal, that the lightly pigmented areas usually expand considerably as individuals age. By their application of pigmentation patterns for subspecific differentiation of Tiger
Salamander populations, we can reasonably infer that these authors considered pigmentation patterns to be \pm stable within particular populations. Observations on captive Tiger Salamanders made between 1977 and 1997 have provided an opportunity to test this by documenting the scale and pattern of the changes in skin pigmentation over time on individual animals (below).

A Tiger Salamander was captured as it and many others of its species (several hundred?) crossed a rainsoaked roadway in a sandy Lodgepole Pine (Pinus contorta) forest in Bow Valley Provincial Park in the eastern foothills of the Rocky Mountains near Canmore, Alberta at ca. 24:00 hours on 17 August 1977. The animal was a full-developed adult measuring $240 \mathrm{~mm}$ in total length (Fig. 1). These salamanders constitute the highest elevation Tiger Salamander population (ca. 1,312 $\mathrm{m}$ asl) known in Canada. Since the altitudinal foreshortened active season for these amphibians lasts only a few months each year (mid-May to early September?) and Tiger Salamanders transform into adulthood in later summer at about $50-60 \mathrm{~mm}$ in total length (Smith 1961), it seems most unlikely that this animal could have developed so substantially had it transformed in 1977. Presumably, then, the salamander transformed into adulthood no later than May/June 1976. 


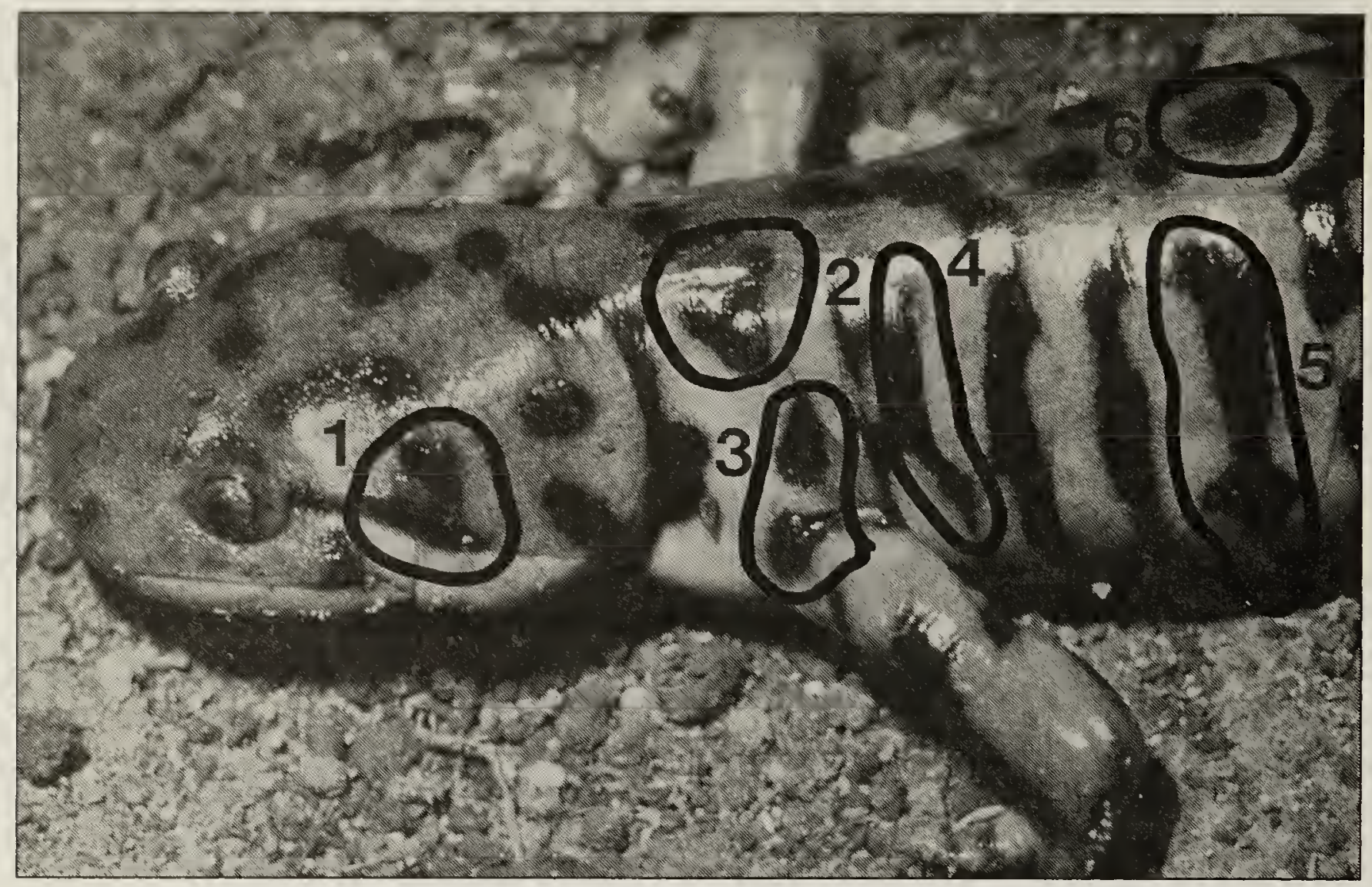

Figure 1. Male Ambystoma tigrinum from Bow Valley Park, Alberta shortly after capture (October 1977). Numbered polygons indicate representatives sites of pigmentation change.

C. Wallis

This male Tiger Salamander has been maintained indoors at room temperature in a large, sand-bot- tomed terrarium with a shallow pool at one end and a board for shelter at the other. It is fed irregularly with a

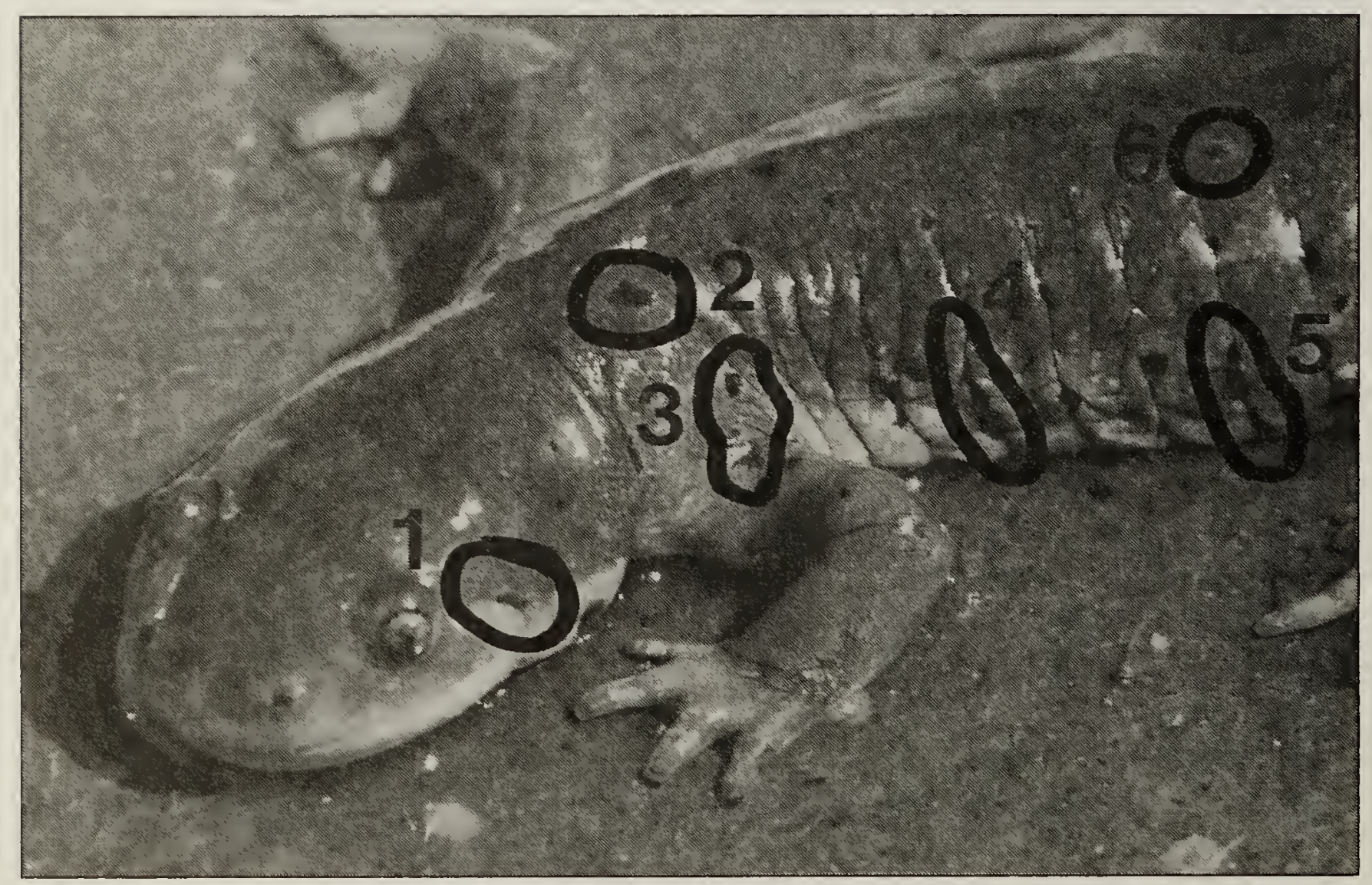

Figure 2. Male Ambystoma tigrinum (same animal as Fig. 1) ten years after capture (April 1987); note significantly reduced black markings on dorsum and sides and darker base colour of skin. Numbered polygons indicate representatives sites of pigmentation change. 


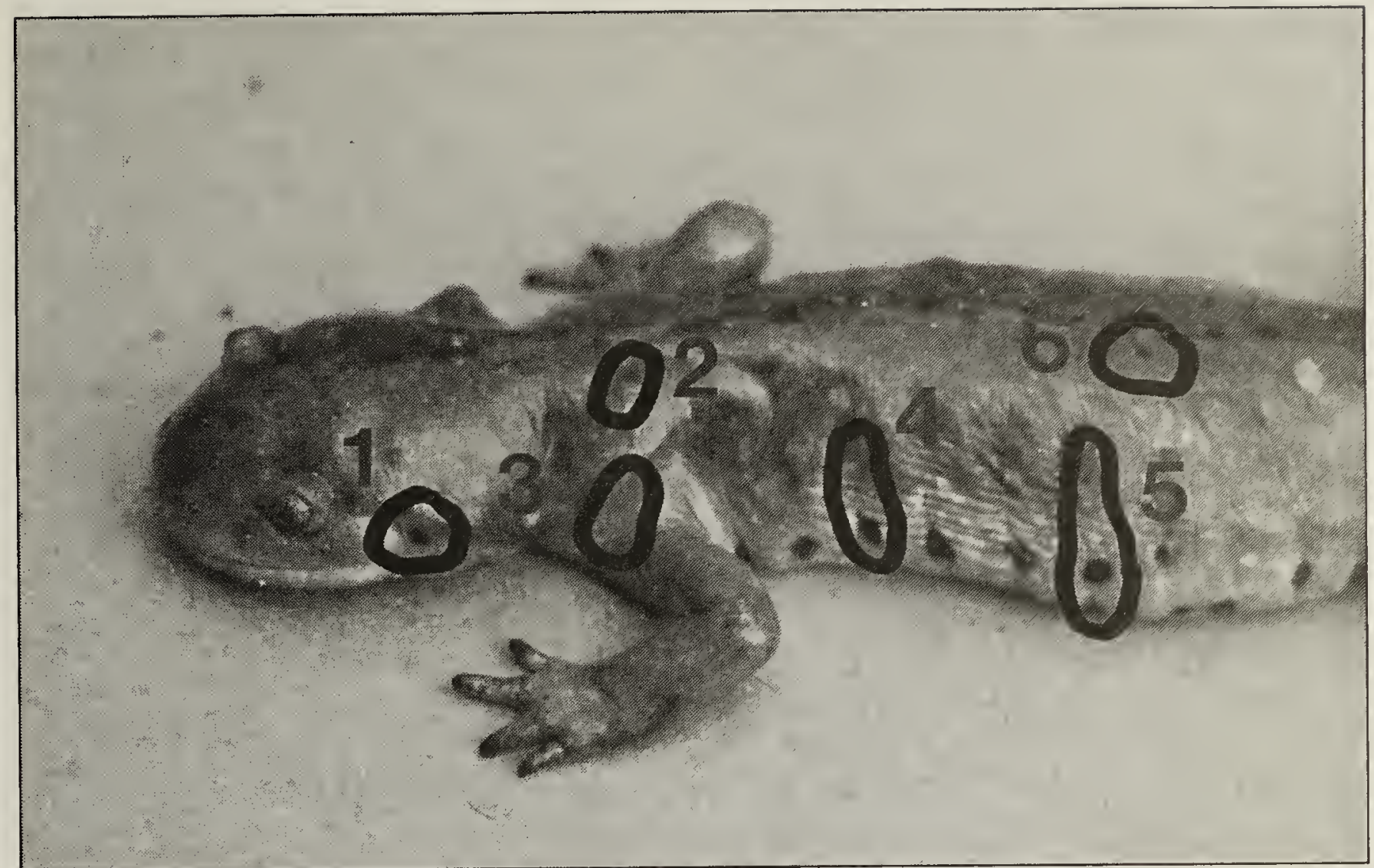

Figure 3. Male Ambystoma tigrinum (same animal as Fig. 1) 20 years after capture (October 1997); note continued but lessened rate of reduction in black markings on dorsum and sides. Numbered polygons indicate representatives sites of pigmentation change.

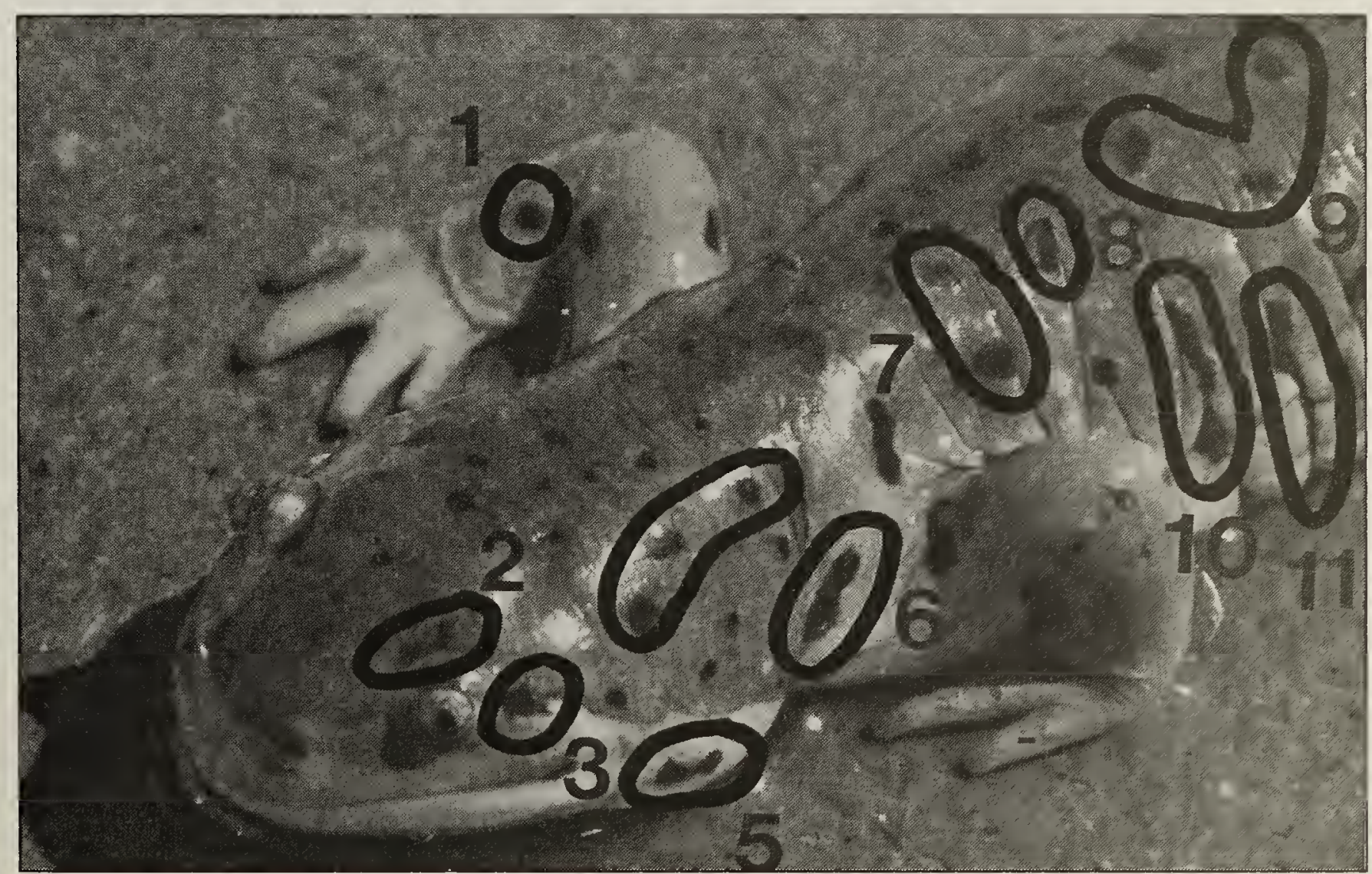

Figure 4. Adult female Ambystoma tigrinum after 3.5 years of captivity (April 1987); note reduced coverage of black markings on dorsum and sides and darker base colour of skin than recently captured male illustrated in Fig. 1. Numbered polygons indicate representatives sites of pigmentation change. 


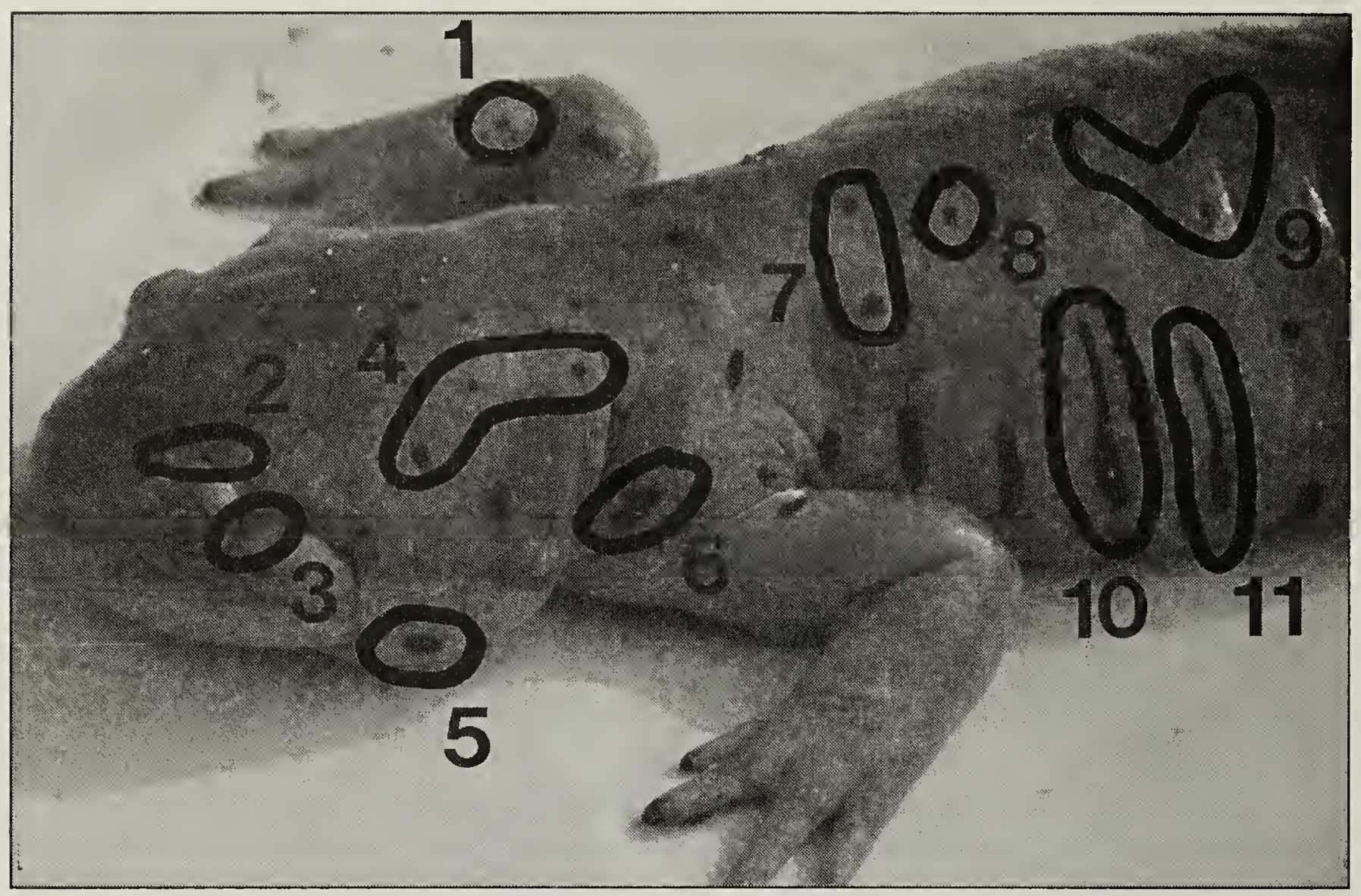

Figure 5. Adult female Ambystoma tigrinum (same animal as Fig. 1) after eight years of captivity (October 1991); note reduced coverage of black markings on dorsum and sides and darker base colour of skin. Numbered polygons indicate representatives sites of pigmentation change.

variety of meat items including worms, table scraps and cat food. The animal has remained active year-round since 1977 and moves throughout its enclosure at all hours of the day and night. It has excavated and maintains a network of tunnels in the sand which it enters from beneath the log. It spends much of each day peering out from the tunnel entrance and emerges rapidly in response to the terrarium light being turned on and/or to nearby human activity. The salamander aggressively snaps at and seizes any moving object within the terrarium (fingers, a spoon, etc.) in pursuit of potential food items.

A second Tiger Salamander, a 230 $\mathrm{mm}$ (total length) adult female, was obtained from the Bow Valley Park population in October 1983 and until its death eight years later (1 October 1991), was kept with the older male. Interaction between the two was minimal except when the rapid movements of one (e.g. when eating) would initiate aggressive snapping by the other.

The relative extent and pigmentation pattern of the female at the time of capture was very similar to that of the male in 1977 (Fig. 1; personal observation). Photographs of the salamanders were taken at intervals during their captivity $(1977,1983$, 1986, 1987, 1989, 1990, 1991 and annually since 1994) in order to document pigmentation changes.

\section{Results}

Fig. 2 illustrates the dramatic reduction in the size and number of black markings on the dorsum and sides of the male Tiger Salamander after 10 years of captivity (April 1987). The base colour of the skin of this animal also changed from a light yellowish olive to a dusky olive brown. The 1983 photographs (not reproduced due to poor quality) indicate that the majority of pigmentation 
change occurred within the first six years. The decline in size and number of black markings between 1987 and 1997 is slight (Figs. 2 and 3).

The largest black markings remaining after ten years are located in the costal grooves of the male $\mathrm{Ti}$ ger Salamander. Although reduction in the intensity, number and size of black spots has continued on the head and legs, it appears to have proceeded very slowly after the six to ten year point (Figs. 2 and 3 ).

Faded black marks along the sides of the female also are evident in a comparison of 1987 and 1991 photos (Figs. 4 and 5). Again, the majority of pigment change appears to have occurred in the first few years ( 2 to 3 years?) of captivity. By November 1986 the female exhibited significantly less dark pigmentation than is typical of mature, wild Blotched Tiger Salamanders (A. tigrinum melanostictum Baird), the westernmost Canadian subspecies to which the Bow Valley Park population belongs (personal observation; photographs not reproduced due to poor quality). The male (and the female to a lesser degree) more closely resemble the Gray Tiger Salamander (A. tigrinum diaboli Dunn), a relatively plainly marked subspecies which is found in central North America, extending northward into Manitoba and Saskatchewan (Gehlback 1967, Cook 1984).

Many factors beyond the passage of time could have a bearing on the pigmentation change of these Tiger Salamanders. Their year-round activity, their unnatural and irregular diet, their high frequency of diurnal, above-ground activity and the physical conditions of their confinement may have played a role individually or in combination. Regardless of the cause, it is evident that significant pigmentation pattern changes do occur and do so in a relatively short period of time. Caution, therefore, must be exercised in subspecifically assigning individual Tiger Salamanders for which the life history is poorly known or is suspected to be abnormal.

The male salamander observed here apparently represents the oldest wild or captive Tiger Salamander known (21.5+ years). No references to animals more than about 15 years of age have been found. This Iongevity record is all the more remarkable when one considers that it is likely physically active for more than twice as long each year than wild members of its native population.

Acknowledgements Cliff Wallis of Calgary generously provided permission for the use of his 1977 photograph of the male animal from which Fig. 1 was produced. The female specimen was obtained with the assistance of Eric Kuhn of Bow Valley Provincial Park, Alberta. Francis Cook, former Curator of Herpetology, Canadian Museum of Nature, provided literature references, herpetological and other valuable assistance during this undertaking.

\section{References}

COOK, F.R. 1980. Introduction to Canadian amphibians and reptiles. National Museum of Natural Sciences, Ottawa. 200 pp.

DUNN, E.R. 1940. The races of Ambystoma tigrinum. Copeia 3: 154-162.

GEHLBACK, F.R. 1967. Ambystoma tigrinum, in: Catalogue of American amphibians and reptiles 52: 1-4.

SMITH, P.S. 1961. The amphibians and reptiles of Illinois. Illinois Natural History Survey Bulletin 28, Illinois Natural History Survey, Urbana.

STEBBINS, R.C. 1966. A field guide to western reptiles and amphibians. Houghton Mifflin, Boston. 279 pp. 